\title{
A probabilistic modeling approach to assess human inhalation exposure risks to airborne aflatoxin $\mathrm{B}_{1}\left(\mathrm{AFB}_{1}\right)$
}

\author{
Chung-Min Liao*, Szu-Chieh Chen
}

\author{
Ecotoxicological Modeling Center, Department of Bioenvironmental Systems Engineering, National Taiwan University, Taipei, \\ Taiwan 10617, Republic of China
}

Received 11 October 2004; received in revised form 14 May 2005; accepted 14 May 2005

\begin{abstract}
To assess how the human lung exposure to airborne aflatoxin $B_{1}\left(A F B_{1}\right)$ during on-farm activities including swine feeding, storage bin cleaning, corn harvest, and grain elevator loading/unloading, we present a probabilistic risk model, appraised with empirical data. The model integrates probabilistic exposure profiles from a compartmental lung model with the reconstructed dose-response relationships based on an empirical three-parameter Hill equation model, describing $\mathrm{AFB}_{1}$ cytotoxicity for inhibition response in human bronchial epithelial cells, to quantitatively estimate the inhalation exposure risks. The risk assessment results implicate that exposure to airborne $\mathrm{AFB}_{1}$ may pose no significance to corn harvest and grain elevator loading/unloading activities, yet a relatively high risk for swine feeding and storage bin cleaning. Applying a joint probability function method based on exceedence profiles, we estimate that a potential high risk for the bronchial region (inhibition $=56.69 \%$ with $95 \%$ confidence interval $(\mathrm{CI}): 35.05-72.87 \%$ ) and bronchiolar region (inhibition $=44.93 \%$ with $95 \%$ CI: $21.61-66.78 \%$ ) is alarming during swine feeding activity. We parameterized the proposed predictive model that should encourage a risk-management framework for discussion of carcinogenic risk in occupational settings where inhalation of $\mathrm{AFB}_{1}$-contaminated dust occurs.
\end{abstract}

(C) 2005 Elsevier Ltd. All rights reserved.

Keywords: Aflatoxins; Mycotoxins; Risk assessment; Lung; Probabilistic

\section{Introduction}

Large gaps remain in the knowledge base needed to conduct quantitative risk assessment for inhaled mycotoxins (Wu, 2004). Case reports and studies of agricultural workers indicate that certain health effects occur from inhalation of molds that are due at least in part to mycotoxins. There are several case reports and epidemiological articles in which toxin-producing molds have been reported to be associated with health effects in

\footnotetext{
*Corresponding author. Tel.: + 886223634512 ; fax: +886223626433 .

E-mail address: cmliao@ntu.edu.tw (C.-M. Liao).
}

indoor environments. The fungus Aspergillus flavus mainly produces aflatoxins. Aflatoxin $\mathrm{B}_{1}\left(\mathrm{AFB}_{1}\right)$, the most toxic of the aflatoxins, a mycotoxin contaminant commonly found in a variety of foods and feeds, is immunotoxic and carcinogenic in many animal models and is strongly suspected to be a human carcinogen (Bondy and Pestka, 2000). Although $\mathrm{AFB}_{1}$ is a wellstudied mycotoxin, exposures to $\mathrm{AFB}_{1}$-containing dust have not been reported in indoor environments, and it is not known whether exposure to $\mathrm{AFB}_{1}$ poses a health risk in indoor environments.

High concentrations of the carcinogen $\mathrm{AFB}_{1}$ are commonly found in respirable, airborne dust, and inhaled $\mathrm{AFB}_{1}$ has been shown to be a risk factor for 
occupational pulmonary carcinogenesis. There is some epidemiological evidence linking pulmonary exposure to $\mathrm{AFB}_{1}$-laden grain dust with an increase in lung tumor incidence in certain occupational settings (Desai and Ghosh, 2003; Ghosh et al., 1997). Kelley et al. (1997) indicated that in situ $\mathrm{AFB}_{1}$ activation and resultant carcinogenic risk are distinctly possible in occupational settings where inhalation of $\mathrm{AFB}_{1}$-contaminated dust occurs. The fate of $\mathrm{AFB}_{1}$ exposure via the respiratory tract is therefore of interest in an evaluation of potential occupational risk. Coulombe et al. (1991) have used a pharmacokinetic model to determine the disposition of $\mathrm{AFB}_{1}$ bound to respirable grain dust, suggesting that particle association of $\mathrm{AFB}_{1}$ increased the respiratory tract retention of this compound at early time intervals, which might be a factor in the reputed carcinogenic action of this compound in the respiratory tract.

Some evidence suggests that the human lung may be a target tissue for the action of $\mathrm{AFB}_{1}$ (Kelly et al., 1997). Two studies indicated that workers at a peanut- and linseed-processing plant, who were exposed to 0.04-2.5 $\mu \mathrm{g}$ of airborne $\mathrm{AFB}_{1}$ per 45-h week, experienced a higher incidence of upper respiratory (trachea and bronchus) tumors compared to unexposed cohorts (Van Nieuwenhuize et al., 1973). A more comprehensive retrospective study showed no excess of respiratory cancer in workers at livestock feed processing plants exposed to an estimated $170 \mathrm{ng}$ airborne $\mathrm{AFB}_{1}$ per day (Olsen et al., 1988). Agricultural surveys show that $\mathrm{AFB}_{1}$ in dust particles from grain mills can reach concentrations as high as $4708 \mathrm{ppb}$ (McMillian et al., 1978). Predicted occupational exposure in a corn processing plant containing $107 \mathrm{ng}$ of $\mathrm{AFB}_{1} \mathrm{~m}^{-3}$, and the daily occupational exposure to $\mathrm{AFB}_{1}$ was calculated to be from $40-856 \mathrm{ng}$, based on a respiration rate of $1 \mathrm{~m}^{3} \mathrm{~h}^{-1}$ (Burg et al., 1981, 1982). Selim et al. (1998) indicated that airborne $\mathrm{AFB}_{1}$ found in dust collected during harvest and grain loading/unloading ranged from 0.04 to $92 \mathrm{ng} \mathrm{m}^{-3}$ and higher levels of $\mathrm{AFB}_{1}$ were found in the airborne dust samples collected from enclosed animal feeding buildings $\left(5-421 \mathrm{ng} \mathrm{m}^{-3}\right)$ and during bin cleaning (124-4849 $\left.\mathrm{ng} \mathrm{m}^{-3}\right)$. Selim et al. (1998) suggested that farmers and farm workers might be exposed to potentially hazardous concentrations of $\mathrm{AFB}_{1}$, particularly during bin cleaning and animal feeding in enclosed buildings.

The objectives of this study are twofold: (1) to conduct an environmental risk assessment based on the USEPA methodology, and (2) to address the uncertainties by using a probabilistic approach to risk characterization that yields quantitative estimates of the risks themselves and also of their associated uncertainties. We reanalyze published data of airborne $\mathrm{AFB}_{1}$ measurements during selected on-farm activities and incorporate a compartmental lung model to estimate the $\mathrm{AFB}_{1}$ concentrations in lung cells. We combine pre- dicted lung cell concentrations and a dose-response relationship derived from published experimental studies on human lung cells allowing us to assess risk endpoint. To determine overall uncertainty in predicted risks, the uncertainties resulting from the assessments of exposure and dose-response are propagated through the risk characterization process using Monte Carlo (MC) analysis.

\section{Material and methods}

Our probabilistic risk assessment framework is divided into four phases (Fig. 1) and is described in the subsequent sections.

\subsection{Problem formulation: data reanalysis}

The occupational settings focus on four selected onfarm activities including indoor: swine feeding and storage bin cleaning and outdoor: corn harvest and grain elevator loading/unloading. The major database is adopted from Burg et al. (1982) and Selim et al. (1998). The size distributions of airborne Aspergillus spp. in indoor and outdoor activities are reanalyzed and optimal fitted to the published data adopted from Gorny et al. (1999) and Sanchez-Monedero and Stentiford (2003). AFB 1 concentration distributions of indoor/outdoor on-farm activities also determined followed the fitted size distributions along with the reported concentration data. We use Kolmogorov-Smirnov $(\mathrm{K}-\mathrm{S})$ statistics to optimize the goodness-of-fit of distribution of observed data by using the Statistica ${ }^{\circledR}$ software package (StatSoft, Tulsa, OK, USA).

\subsection{Exposure analysis}

We use a compartmental lung model to estimate $\mathrm{AFB}_{1}$ concentration in lung tissue (Liao et al., 2003). We divided the human respiratory tract (HRT) into five major compartments from the suggestion of ICRP66 (ICRP, 1994): (i) the nasal passage (ET 1$)$, comprising the anterior nose and the posterior nasal passages; (ii) the pharynx $\left(\mathrm{ET}_{2}\right)$, comprising larynx and mouth; (iii) the bronchial region (BB), comprising the airway from the trachea, main bronchi, and intrapulmonary bronchi; (iv) the bronchiolar region (bb), comprising the bronchioles and terminal bronchioles; and (v) the alveolar-interstitial region (AI), comprising the airway from respiratory bronchioli through alveolar sacs. Followed by the principle of mass balance, the dynamic equations of inspiratory oral cavity (IOC) varying with particle size range $k$ and time $t$ to each regional compartment are given a by a linear dynamic equation (Liao et al., 2003; Chen et al., 2004). We solve the linear dynamic equation explicitly as $\mathrm{AFB}_{1}$ concentrations 


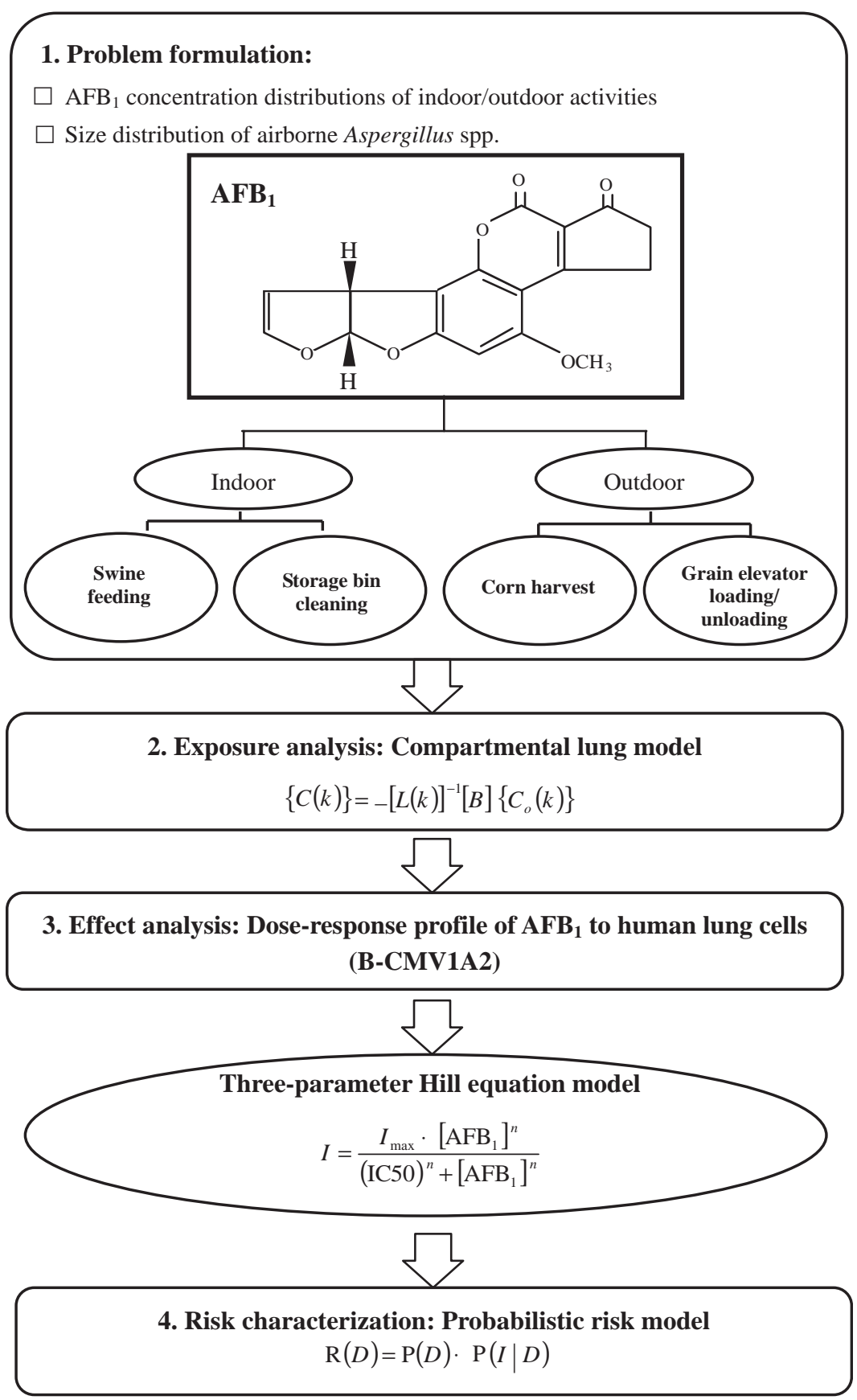

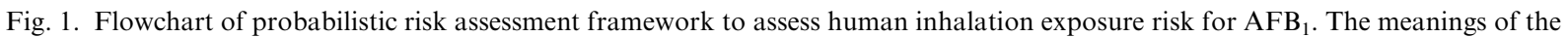
symbols are described in the text.

reach steady-state and yield the steady state $\mathrm{AFB}_{1}$ concentration in each compartment as

$\{C(k)\}=-[L(k)]^{-1}[B]\left\{C_{I}(k)\right\}$, where $\{C(k)\}=\left\{C_{1}(k) C_{3}(k) C_{4}(k) C_{5}(k)\right\}^{\mathrm{T}}$ is the state variable vector of $\mathrm{AFB}_{1}$ concentrations in compartments $\mathrm{ET}_{1}, \mathrm{BB}, \mathrm{bb}$, and $\mathrm{AI}$, respectively $\left(\mathrm{ng} \mathrm{m}^{-3}\right) ; C_{\mathrm{I}}(k)$ is the input $\mathrm{AFB}_{1}$ concentrations $\left(\mathrm{ng} \mathrm{m}^{-3}\right)$; the constant 
input matrix $[B]=\operatorname{diag}\left[Q / V_{1}, 0,0,0\right]$; and the state matrix $[L(k)]$ has the form as

$$
\left[\begin{array}{cc}
-\lambda_{\mathrm{d}_{1}}(k)-\lambda_{\mathrm{s}_{1}}(k)-\lambda_{\mathrm{im}_{1}}(k) & \beta_{13} \frac{Q}{V_{1}} \\
-\varepsilon_{1}(k) \frac{Q}{V_{1}}-\beta_{31} \frac{Q}{V_{1}}-\frac{Q}{V_{1}} & -\lambda_{\mathrm{d}_{3}}(k)-\lambda_{\mathrm{s}_{3}}(k)-\lambda_{\mathrm{im}_{3}}(k) \\
\beta_{31} \frac{Q}{V_{3}} & -\varepsilon_{3}(k) \frac{Q}{V_{3}}-\beta_{43} \frac{Q}{V_{3}}-\beta_{13} \frac{Q}{V_{3}} \\
0 & \beta_{43} \frac{Q}{V_{4}} \\
0 & 0
\end{array}\right.
$$

particulate matter deposition for HRT (Liao et al., 2003; Chen et al., 2004) to estimate the lung deposition of

$\left.\begin{array}{cc}\hline 0 & 0 \\ \beta_{34} \frac{Q}{V_{3}} & 0 \\ -\lambda_{\mathrm{d}_{4}}(k)-\lambda_{\mathrm{s}_{4}}(k)-\lambda_{\mathrm{im}_{4}}(k) & \beta_{45} \frac{Q}{V_{4}} \\ -\varepsilon_{4}(k) \frac{Q}{V_{4}}-\beta_{54} \frac{Q}{V_{4}}-\beta_{34} \frac{Q}{V_{4}} & -\lambda_{\mathrm{d}_{5}}(k)-\lambda_{\mathrm{s}_{5}}(k)-\lambda_{\mathrm{im}_{5}}(k) \\ \beta_{54} \frac{Q}{V_{5}} & -\varepsilon_{5}(k) \frac{Q}{V_{5}}-\beta_{45} \frac{Q}{V_{5}}-C_{L}(t)\end{array}\right]$

in that $Q$ is the breathing rate $\left(\mathrm{cm}^{3} \mathrm{~h}^{-1}\right) ; V_{i}$ is the volume of compartment $i\left(\mathrm{~cm}^{-3}\right) ; \beta_{n}$ is the transition coefficient from compartments $n$ to $m ; \lambda_{\mathrm{d}_{i}}(k), \lambda_{\mathrm{s}_{i}}(k)$, and $\lambda_{\mathrm{im}_{i}}(k)$ represent turbulent diffusive deposition rate, gravitational settling rate, and inertial impaction rate, respectively, in the $k$ th size range in the compartment $i\left(\mathrm{~s}^{-1}\right)$; $\varepsilon_{i}(k)$ is the interception deposition efficiency in the $k$ th size range in the compartment $i$; and $\lambda_{L}(t)$ is the timedependent fungal spores clearance rate in the compartment AI $\left(\mathrm{s}^{-1}\right)$.

The major route of entry into the body of airborne $\mathrm{AFB}_{1}$ in the on-farm activities is inhalation, and this causes deposition and accumulation in HRT. We employ turbulent diffusive deposition rate equations of particulate $\mathrm{AFB}_{1}$. Inspiratory/expiratory oral cavity (IOC/EOC) and inspiratory/expiratory nasal-pharyngeal (INP/ENP) were treated as the breathing patterns during on-farm activities. Other physiological parameters, including clearance rate, transfer coefficient between lung compartments, and airways reference values, are obtained from ICRP66 (ICRP, 1994). Table 1 summarizes the lung physiological parameters and the durations, frequencies and respiratory rates for four different on-farm activities used in the present analysis. We considered that storage bin cleaning, corn harvest, and grain elevator loading/unloading are heavy exercises and swine feeding is a light exercise (Table 1).

Table 1

Lung physiological parameters used in the model simulation and the durations, frequencies and respiratory rates for four different onfarm activities

\begin{tabular}{|c|c|c|c|}
\hline Lung physiological parameter ${ }^{\mathrm{a}}$ & Description & & Representation values \\
\hline$Q_{\mathrm{f}}$ & Breathing frequency & & 15,20 breaths $\min ^{-1}$ \\
\hline$V_{\mathrm{t}}$ & Tidal volume & & $1.33,3 \mathrm{~L}$ \\
\hline$C_{L}$ & Clearance rate by phagocyte & & $8.3 \times 10^{-3} h^{-1}$ \\
\hline$\beta_{i j}$ & $\begin{array}{l}\text { Transfer coefficient between } \\
\text { compartments } i \text { and } j\end{array}$ & & $0.9-1.1$ \\
\hline$D_{1}, D_{2}, D_{3}, D_{4}, D_{5}$ & Diameter of airways & & $0.5,2.3,1.2,0.1,0.05 \mathrm{~cm}$ \\
\hline$n_{1}, n_{2}, n_{3}, n_{4}, n_{5}$ & Number of airways & & $1,1,1,6.5 \times 10^{4}, 4.5 \times 10^{7}$ \\
\hline$V_{1}, V_{2}, V_{3}, V_{4}, V_{5}$ & Volume of compartments in lung & & $\begin{array}{l}5.8,82.1,94.6,510.2, \\
1580.4 \mathrm{~cm}^{3}\end{array}$ \\
\hline On-farm activity & Duration $\left(\mathrm{h} \mathrm{d}^{-1}\right)$ & $\begin{array}{l}\text { Frequency } \\
\left(\mathrm{d} \mathrm{yr}^{-1}\right)\end{array}$ & Respiratory rate $\left(\mathrm{m}^{3} \mathrm{~h}^{-1}\right)^{\mathrm{a}}$ \\
\hline Swine feeding & $2^{\mathrm{b}}$ & $365^{\mathrm{b}}$ & $1.31 \pm 0.14$ (light exercise) \\
\hline Storage bin cleaning & $4 /$ bin $^{b}$ & 2 bins $^{\mathrm{b}}$ & $2.54 \pm 0.44$ (heavy exercise) \\
\hline Corn harvest & $12^{\mathrm{b}}$ & $7^{\mathrm{b}}$ & $2.54 \pm 0.44$ \\
\hline Grain elevator loading/unloading & $12^{\mathrm{c}}$ & $7^{\mathrm{c}}$ & $2.54 \pm 0.44$ \\
\hline
\end{tabular}

aAdapted from ICRP66 (ICRP, 1994).

${ }^{\mathrm{b}}$ Adapted from Selim et al. (1998).

${ }^{\mathrm{c}}$ Estimated from Selim et al. (1998). 


\subsection{Effect analysis}

Inhibition response of human lung cells in relation to cytotoxicity of $\mathrm{AFB}_{1}$ at low doses for the bronchial epithelial cells is adapted from the published literature in that the cytochrome P-450 (CYP) 1A2-expressing human lung cells (B-CMV1A2) was the most susceptible cell type to the cytotoxic effects of $\mathrm{AFB}_{1}$ (Van Vleet et al., 2001, 2002). They concluded that human lung cells expressing these CYP isoforms are capable of activating $\mathrm{AFB}_{1}$, even at low environmentally relevant concentrations. They also suggested that any assessment of risk posed by inhaled $\mathrm{AFB}_{1}$ should take into account the relative expression of these isoforms in the human lung and it is possible that inhalation of $\mathrm{AFB}_{1}$ may result in an increased risk of lung cancer in exposed persons.

Van Vleet et al. (2002) used an empirical threeparameter Hill equation model to represent the cytotoxicity plots of $\%$ inhibition versus $\mu \mathrm{M} \mathrm{AFB}_{1}\left(1 \mathrm{ng} \mathrm{m}^{-3}\right.$ of $\mathrm{AFB}_{1}$ is equal to $3.2 \times 10^{-6} \mu \mathrm{M} \mathrm{m}^{-3}$ based on the molecular weight of $\mathrm{AFB}_{1}=312.3 \mathrm{~g} \mathrm{M}^{-1}$ )

$I=\frac{I_{\max } \times\left[\mathrm{AFB}_{1}\right]^{0.774}}{[\mathrm{IC} 50]^{0.774}+\left[\mathrm{AFB}_{1}\right]^{0.774}},\left(r^{2}=0.998\right)$,

where $I$ is the measured response (\% inhibition), IC50 is the $\mathrm{AFB}_{1}$ concentration yielding half of the maximal response $\left(I_{\max }=83.344 \%\right.$ inhibition $)$ in that $\mathrm{IC} 50=$ $0.065 \pm 0.02($ mean $\pm \mathrm{SD}), 0.774$ is the Hill coefficient $(n)$ which is a measure of cooperativity in which an $n<1$ represents a supralinear response. We treated IC50 in Eq. (3) probabilistically to account for the inherent uncertainty that arises from a number of sources, including the limited number of observations and limited sample size within treatment sets.

To account for this uncertainty, we construct a distribution for the input variable of IC50. We determine normal distribution for IC50 and incorporate the distribution into the MC simulation to obtain 2.5th and 97.5 th percentiles as the $95 \%$ confidence interval (CI) for reconstructed dose-response profile. Uncertainty and/or variability were not considered for the reported Hill coefficient. This was unfortunate but unavoidable since the Hill coefficient from the published study was reported only as an average value. As a result, the risk curves and CI reported here do not incorporate this source of uncertainty. Applying the Hill equation model, the cumulative distribution function (cdf) of predicted cytotoxicity ( $\%$ inhibition) function for a given $\mathrm{AFB}_{1}$ dose in human lung cell $(D), F(I \mid D)$, could be expressed symbolically as a conditional cdf:

$F(I \mid D)=\Phi\left(\frac{83.344 \times D^{0.774}}{(\mathrm{IC} 50)^{0.774}+D^{0.774}}\right)$,

where $\Phi(\cdot)$ is the cumulative standard normal distribution.

\subsection{Risk characterization}

Risk characterization is the phase of risk assessment where the results of the exposure and quantitative effects assessments are integrated to provide an estimate of risk for the population under study. In this case, it entails combining the exposures, measured as $\mathrm{AFB}_{1}$ dose in human lung cell, with the quantitative dose-response relationship between lung cell $\mathrm{AFB}_{1}$ dose and associated $\%$ inhibition determined from the experimental studies.

Risk at a specific $\mathrm{AFB}_{1}$ dose in the lung cell $(D)$ can be calculated as the proportion of the lung cell expected to have that cell concentration multiplied by the conditional probability of \% inhibition, at a given dose, $D$. This results in a joint probability function (JPF) or exceedence profile, which describes the probability of exceeding the concentration associated with a particular degree of effect. Graphic display of the JPF also provides a means of assessing how alterations in ambient concentrations due to management efforts would affect the risk assessment. This can be expressed mathematically as a probabilistic risk model as

$R(D)=F(D) \times F(I \mid D)$,

where $R(D)$ is the risk at a specific $\mathrm{AFB}_{1}$ dose $D, F(D)$ is the cdf of having lung cell $\mathrm{AFB}_{1}$ dose, and $F(I \mid D)$ is the
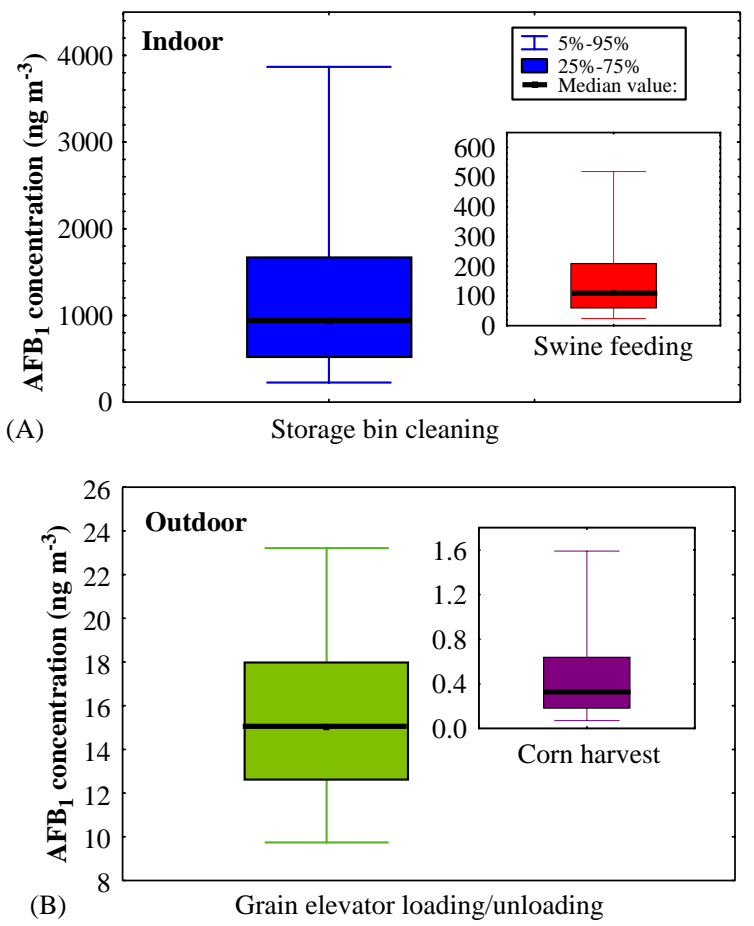

Fig. 2. Box and whisker plots of $\mathrm{AFB}_{1}$ concentration in (A) indoor on-farm activities of storage bin cleaning and swine feeding and in (B) outdoor on-farm activities of grain elevator loading/unloading and corn harvest. 
conditional cdf of the $\%$ inhibition, given lung cell $\mathrm{AFB}_{1}$ dose $D$. A risk diagram was generated from the cumulative distribution of simulation outcomes. Each point on the risk diagram represents both the probability that the chosen proportion of lung cell will be affected and also the frequency with which that level of effect would be exceeded.

\section{Results and discussion}

\subsection{Exposure analysis}

Fig. 2 shows the box plots of interquartile and 50th percentile predictions associated with whisker plots indicating 5th- and 95th-percentile predictions of $\mathrm{AFB}_{1}$ levels in on-farm indoor (storage bin cleaning and swine feeding) and outdoor (grain elevator loading/unloading and corn harvest) activities in that the particle size distributions are shown in Fig. 3. Fig. 3 indicates that particle size distributions of $A$. flavus for on-farm indoor activities of swine feeding and storage bin cleaning have a lognormal distribution with a geometric mean diameter of $2.81 \mu \mathrm{m}$ and a geometric standard deviation of 1.65. Gorny et al. (1999) and Sanchez-Monedero and Stentiford (2003) reported that the major $\mathrm{AFB}_{1}$-induced fungal spores of $A$. flavus had their maximum concentrations in the aerodynamic size range $2.1-3.3 \mu \mathrm{m}$.

The distributions of $\mathrm{AFB}_{1}$ level during storage bin cleaning, swine feeding, and corn harvest were more highly skewed at higher concentrations (Fig. 2), indicating that measured $\mathrm{AFB}_{1}$ concentrations had a higher uncertainty as quantified by the variances in that the 5th- and 95th-percentiles predictions for storage bin cleaning and swine feeding are ranged from 225.31 to 3867.65 and 23.97 to $518.79 \mathrm{ng} \mathrm{m}^{-3}$, respectively, during

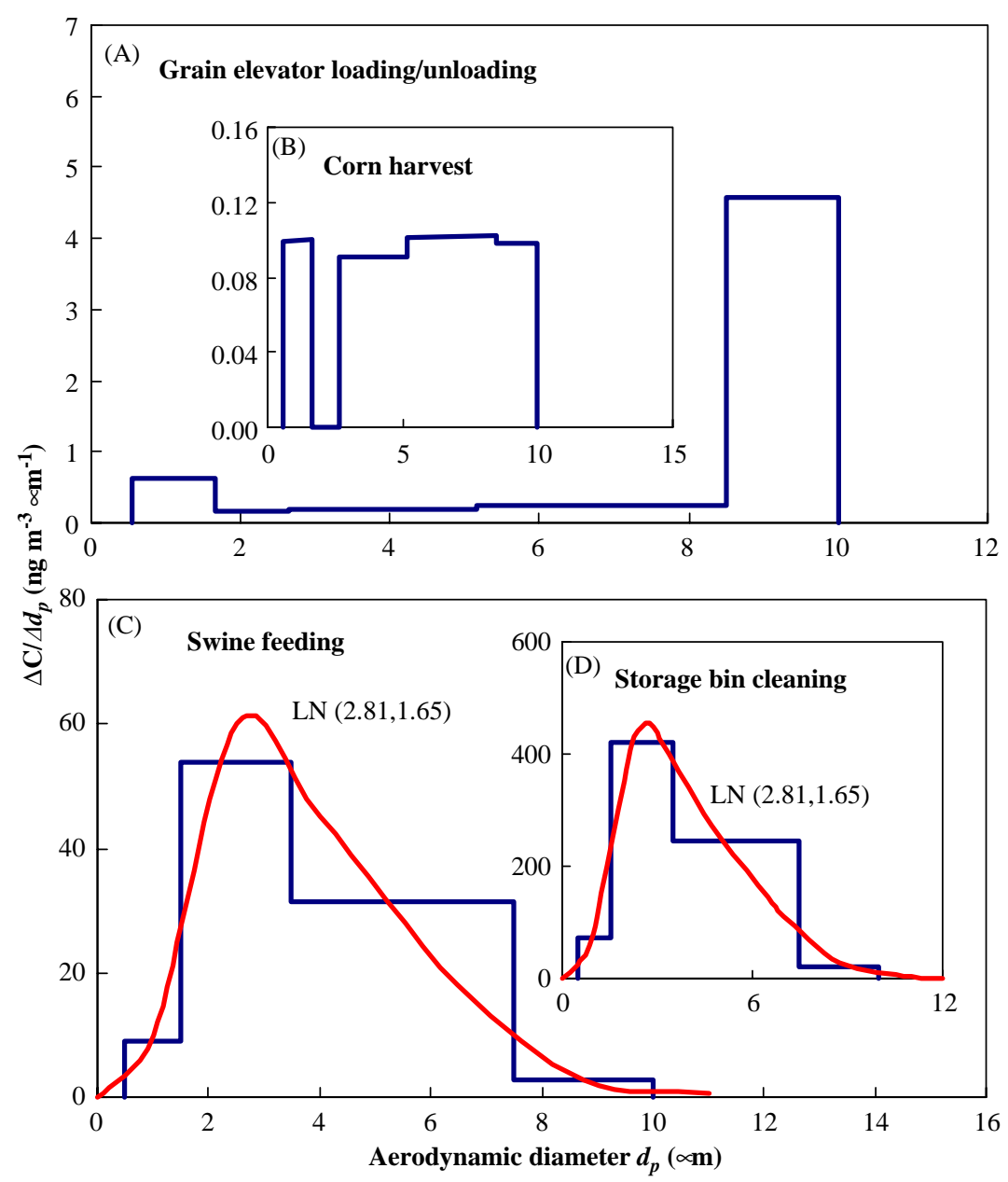

Fig. 3. Aerodynamic diameter distributions of A. flavus of four on-farm activities: (A) grain elevator loading/unloading, (B) corn harvest, (C) swine feeding, and (D) storage bin cleaning in that $\mathrm{LN}(a, b)$ denotes the lognormal distribution with geometric mean diameter $a \mu \mathrm{m}$ and geometric standard deviation $b$. 
indoor on-farm activities; whereas during outdoor onfarm activities ranged from 9.74 to 23.21 and 0.07 to $1.59 \mathrm{ng} \mathrm{m}^{-3}$ for grain elevator loading/unloading and corn harvest, respectively. Fig. 2 also demonstrates that the magnitudes of measured median $\mathrm{AFB}_{1}$ concentrations during indoor activities of storage bin cleaning $\left(10^{3}\right)$ is one order higher than that during swine feeding $\left(10^{2}\right)$, whereas during outdoor activities, the $\mathrm{AFB}_{1}$ level of grain elevator loading/unloading $\left(10^{1}\right)$ is two orders higher than that of corn harvest $\left(10^{-1}\right)$. The differences of $\mathrm{AFB}_{1}$ level at four settings may be due to the existing environmental effects of different temperature and humidity. The higher the humidity, the higher the fungal growth of Aspergillus spores, especially for uncontrolled humidity condition in storage bins.

\subsection{Dose-response model for human lung cells}

The reconstructed dose-response profile (Fig. 4) was implemented by 5000 iterations of a MC simulation providing an adequate fit for the data points of $\mathrm{AFB}_{1}$ concentrations from 0 to $1 \mu \mathrm{M}$ ( $\chi^{2}$ goodness of fit, $P>0.5)$. It can be seen from Fig. 4 that the calculated inhibition concentration inducing 50\% inhibition (IC50) value is $0.065 \mu \mathrm{M}$ with a $95 \%$ CI of 0.03 to $0.11 \mu \mathrm{M}$ from the fitted dose-response model.

At present the dose-response relationships for fungal particles are understood poorly, i.e., the number of particles of each fungal genus or species needed to cause a certain symptom or disease is not known. Therefore, the suitability of published data for dose-response modeling still needs to be justified.

\subsection{Risk estimates for respiratory deposition}

Figs. 5A, C, and E show histograms for the predicted pdfs of $\mathrm{AFB}_{1}$ concentrations in different HRT regions of $\mathrm{BB}, \mathrm{bb}$, and $\mathrm{AI}$ during different indoor and outdoor on-farm activities. The relative skewness and spread in modeled output varied with on-farm activities. A box and whisker plot represents the uncertainty in comparing $\%$ inhibition for different on-farm activities in different HRT regions (Figs. 5B, D, and F). We first reanalyze published data of airborne $\mathrm{AFB}_{1}$ measurements of selected on-farm activities and then incorporate a compartmental lung model to estimate the $\mathrm{AFB}_{1}$ concentrations in lung cells. We solve the linear dynamic equation explicitly as $\mathrm{AFB}_{1}$ concentrations reach steady state and yield the steady-state $\mathrm{AFB}_{1}$ concentration in each compartment as shown in Eq. (1). We thus employ the MC simulation to predict the pdfs value of $\left\{C_{I}(k)\right\}$ based on the input parameter of $\{C(k)\}$ featuring a lognormal distribution.

We calculated the overall expected inhibition subjected to a mean $\mathrm{AFB}_{1}$ level to highlight the expected risk in different HRT regions during various on-farm

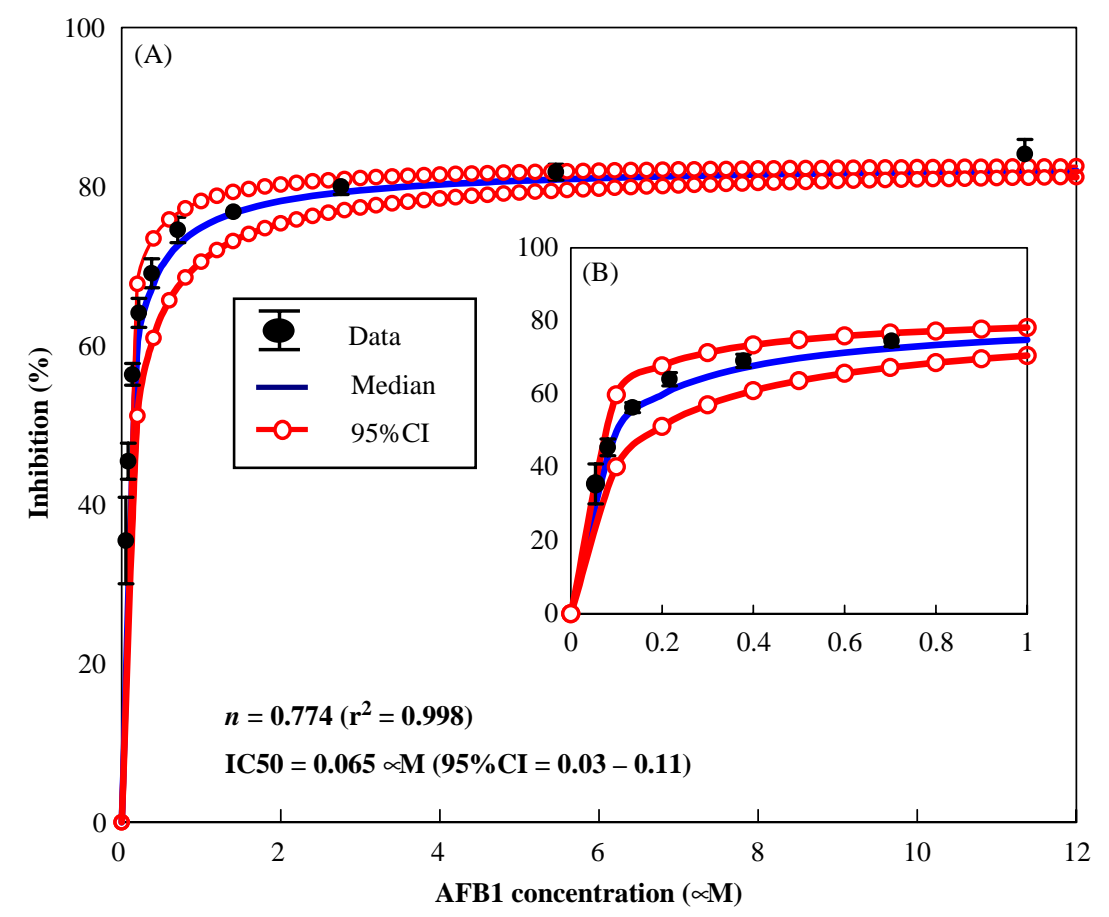

Fig. 4. Reconstructed dose-response profile with $95 \%$ confidence interval optimally fitted by three-parameter Hill model equation in that $\mathrm{AFB}_{1}$ concentrations ranged from (A) 0 to $12 \mu \mathrm{M}$ and (B) 0 to $1 \mu \mathrm{M}$. 

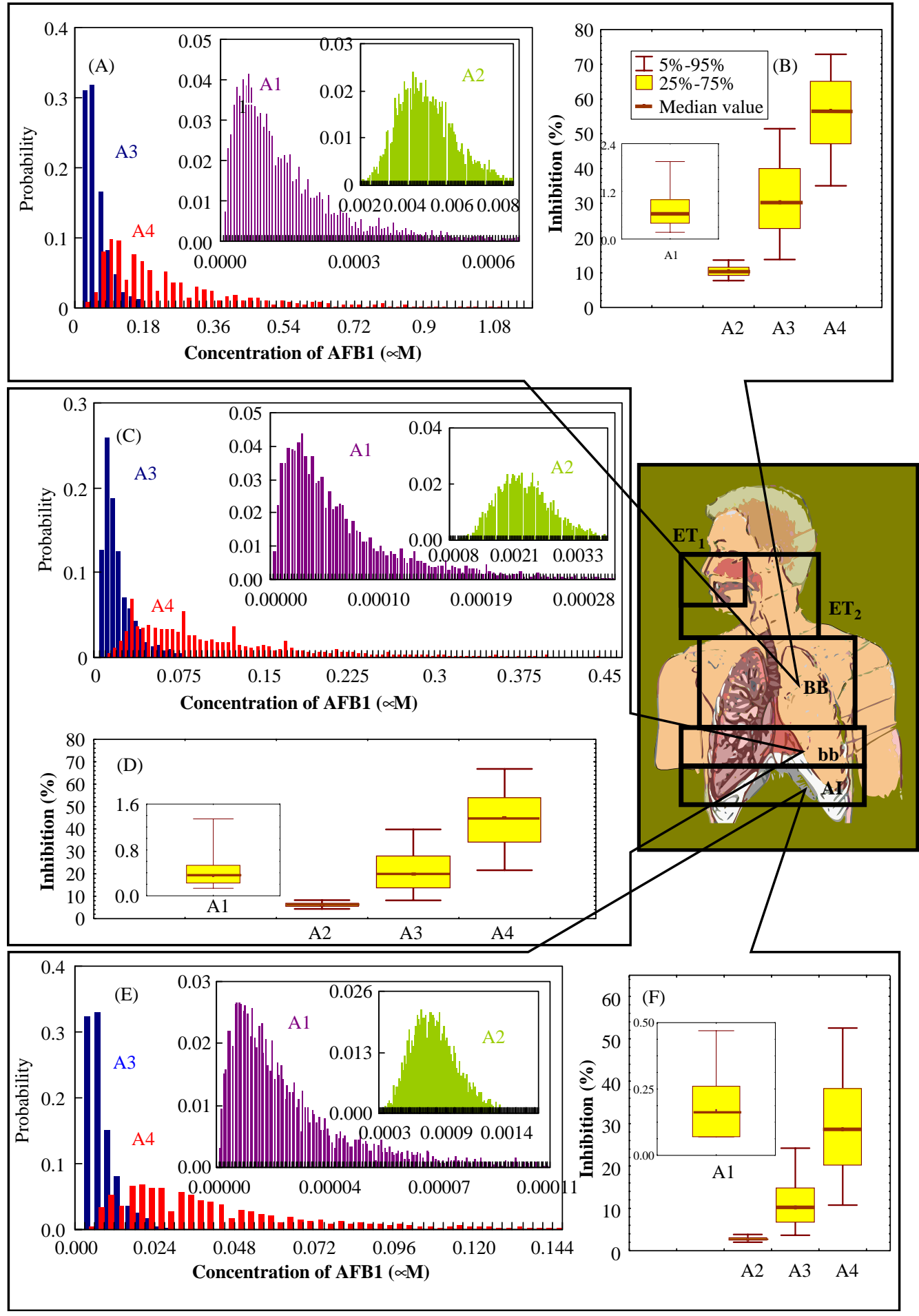

Fig. 5. Probabilistic density functions predicted for $\mathrm{AFB}_{1}$ concentrations in different HRT regions: (A) BB, (C) bb, and (E) AI for four on-farm activities in that $\mathrm{A} 1=$ corn harvest, $\mathrm{A} 2=$ grain elevator loading/unloading, $\mathrm{A} 3=$ storage bin cleaning, and $\mathrm{A} 4=\mathrm{swine}$ feeding. Box and whisker plots represent the uncertainty in comparing \% inhibition for different on-farm activities in different HRT regions: (B) $\mathrm{BB}$, (D) bb, and (F) AI. 
Table 2

The overall expected inhibition $(I(\%))$ subjected to a mean $\mathrm{AFB}_{1}$ level $(\mu \mathrm{M})$ in different lung regions of $\mathrm{BB}$, bb, and $\mathrm{AI}$ during four different on-farm activities

\begin{tabular}{|c|c|c|c|c|}
\hline & Swine feeding & Storage bin cleaning & Corn harvest & Grain elevator loading/unloading \\
\hline \multicolumn{5}{|l|}{ BB } \\
\hline $\mathrm{AFB}_{1}$ & $1.59 \times 10^{-1}$ & $2.92 \times 10^{-2}$ & $1.09 \times 10^{-4}$ & $4.90 \times 10^{-3}$ \\
\hline$I$ & $56.69(35.05-72.87)^{\mathrm{a}}$ & $30.37(13.82-51.45)$ & $0.63(0.17-1.95)$ & $10.47(7.77-13.68)$ \\
\hline \multicolumn{5}{|l|}{$\mathrm{bb}$} \\
\hline $\mathrm{AFB}_{1}$ & $7.34 \times 10^{-2}$ & $1.34 \times 10^{-2}$ & $5.12 \times 10^{-5}$ & $2.23 \times 10^{-3}$ \\
\hline$I$ & $44.93(21.61-66.78)$ & $19.90(8.18-39.79)$ & $0.35(0.13-1.34)$ & $6.04(4.39-8.25)$ \\
\hline \multicolumn{5}{|l|}{ AI } \\
\hline $\mathrm{AFB}_{1}$ & $2.60 \times 10^{-2}$ & $4.68 \times 10^{-3}$ & $2.05 \times 10^{-5}$ & $7.78 \times 10^{-4}$ \\
\hline$I$ & $28.62(10.78-52.55)$ & $10.16(3.67-24.21)$ & $0.17(0.07-0.47)$ & $2.79(2.02-3.84)$ \\
\hline
\end{tabular}

${ }^{\mathrm{a}} 95 \% \mathrm{CI}$ is calculated from 2.5 th and 97.5 th-percentiles of $5000 \mathrm{MC}$ simulations.
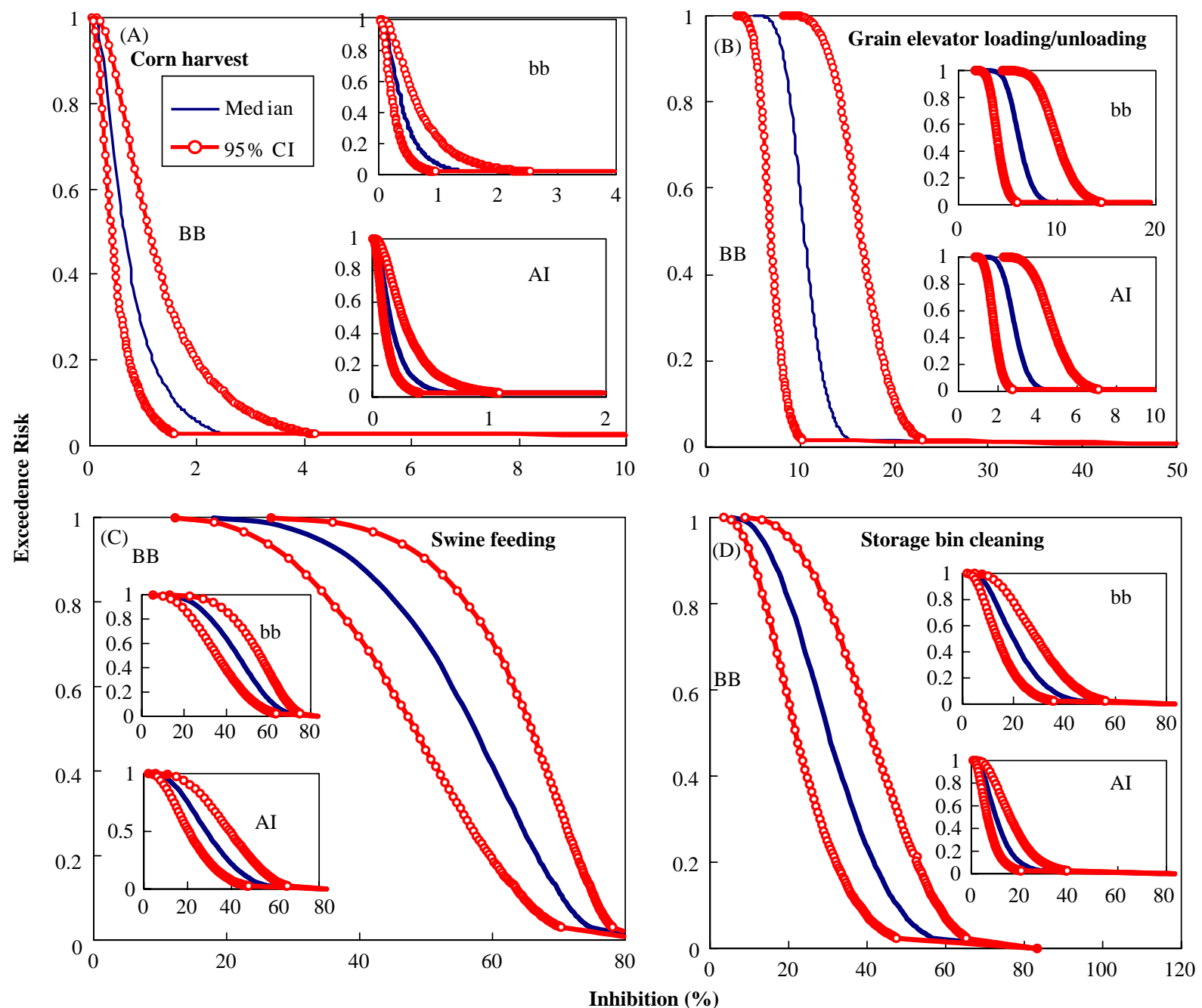

Fig. 6. Exceedence risk diagrams with $95 \%$ confidence interval of four on-farm activities of (A) corn harvest, (B) grain elevator loading/unloading, (C) swine feeding, and (D) storage bin cleaning in different HRT regions of BB, bb, and AI. 
activities (Table 2). Table 2 suggests that the relatively high risk for regions BB $(I=56.69 \%$ with $95 \% \mathrm{CI}$ : $35.05-72.87 \%)$ and bb $(I=44.93 \%$ with $95 \%$ CI: $21.61-66.78 \%$ ) is alarming during swine feeding activity.

Risk curves shown in Fig. 6 indicate the estimated probabilistic of inhibitions of differing on-farming activities for different HRT regions. The plotted probabilities, calculated from the outcome of the MC simulation followed a JPF shown in Eq. (5) describing the exceedence cdfs (Fig. 6) associated with a doseresponse relationship (Fig. 4), taking into account the uncertainty in estimating risk. Fig. 6 demonstrates that the probabilities that $10 \%$ or more of the lung cells in regions $\mathrm{BB}, \mathrm{bb}$, and $\mathrm{AI}$ (risk $=0.1$ ) affected during swine feeding activity are approximately $71 \%, 62 \%$, and $48 \%$, respectively, with $95 \%$ CI of $65-75 \%, 54-70 \%$, and $38-58 \%$, respectively. Generally, for corn harvest, grain elevator loading/unloading, and storage bin cleaning, the probability is 0.1 that at least $0.4-1.6 \%$, $4-13 \%$, and $21-48 \%$ inhibition, respectively, exist for lung cells in $\mathrm{AI}, \mathrm{bb}$, and $\mathrm{BB}$ regions.

We believe that a probabilistic risk-based framework - probability distributions and risk diagrams such as Fig. 6-is an effective representation of state-of-theart results of scientific assessments for human response to airborne $\mathrm{AFB}_{1}$ exposure during on-farm activities. To our knowledge, this risk-based framework has not been addressed until now. Although the suitability and effectiveness of techniques for presenting uncertain results is context dependent, we believe that such probabilistic methods are more valuable for communicating an accurate view of current scientific knowledge to those seeking information for decision-making than assessments that do not attempt to present results in probabilistic framework. We suggest that our probabilistic framework and methods be taken seriously because they produce general conclusions that are more robust than estimates made with a limited set of scenarios or without probabilistic presentations of outcomes, and our modeling technique offers a risk-management framework for discussion of future establishment of limits for respiratory exposure to airborne $\mathrm{AFB}_{1}$.

\section{References}

Bondy, G.S., Pestka, J.J., 2000. Immunomodulation by fungal toxins. Journal of Toxicology and Environmental Health Part B 3, 109-143.

Burg, W.A., Shotwell, O.L., Saltzman, B.E., 1981. Measurements of airborne aflatoxins during the handling of contaminated corn. American Industrial Hygiene Association Journal 42, 1-11.

Burg, W.R., Shotwell, O.L., Saltzman, B.E., 1982. Measurements of airborne aflatoxins during the handling of 1979 contaminated corn. American Industrial Hygiene Association Journal 43, 580-586.
Chen, J.W., Liao, C.M., Chen, S.C., 2004. Compartmental human respiratory tract modeling of airborne dust exposure from feeding in swine buildings. Journal of the Air and Waste Management Association 54, 331-341.

Coulombe, R.A., Huie, J.M., Ball, R.W., Sharma, R.P., Wilson, D.W., 1991. Pharmacokinetics of intratracheally administered aflatoxin $\mathrm{B}_{1}$. Toxicology and Applied Pharmacology 109, 196-206.

Desai, M.R., Ghosh, S.K., 2003. Occupational exposure to airborne fungi among rice mill workers with special reference to aflatoxin producing A. flavus strains. Annals of Agricultural and Environmental Medicine 10, 159-162.

Ghosh, S.K., Desai Manisha, R., Pandya, G.L., Venkaiah, K., 1997. Airborne aflatoxin in the grain producing industries in India. American Industrial Hygiene Association Journal 5, 583-586.

Gorny, R.L., Dutkiewicz, J., Krysinska-Traczyk, E., 1999. Size distribution of bacterial and fungal bioaerosols in indoor air. Annals of Agricultural and Environmental Medicine 6, 105-113.

ICRP, 1994. Human respiratory tract model for radiological protection, a report of a task group of the international commission on radiological protection, ICRP Publication No. 66. Elsevier, New York.

Kelly, J.D., Eaton, D.L., Guengerich, F.P., Coulombe, R.A., 1997. Aflatoxin $B_{1}$ activation in human lung. Toxicology and Applied Pharmacology 144, 88-95.

Liao, C.M., Chen, J.W., Huang, S.J., 2003. Size-dependent $\mathrm{PM}_{10}$ indoor/outdoor/personal relationships for a windinduced naturally ventilated airspace. Atmospheric Environment 37, 3065-3075.

McMillian, W.A., Wilson, D.M., Widstrom, N.W., 1978. Insect damage, aspergillus ear mold, and aflatoxin contamination in south Georgia corn field in 1977. Journal of Environmental Quality 7, 565.

Olsen, J.J., Dragsted, L., Autrup, H., 1988. Cancer risk and occupational exposure to aflatoxins in Denmark. British Journal of Cancer 58, 392-396.

Sanchez-Monedero, M.A., Stentiford, E.I., 2003. Biofiltration at compositing facilities: effectiveness for bioaerosol control. Environmental Science and Technology 37, 4299-4303.

Selim, M.I., Juchems, A.M., Popendorf, W., 1998. Assessing airborne aflatoxin $\mathrm{B}_{1}$ during on-farm grain handling activities. American Industrial Hygiene Association Journal 59, 252-256.

Van Nieuwenhuize, J.P., Herber, R.F.M., de Bruin, A., Meyer, P.B., Duba, W.C., 1973. Aflatoxins epidemiological study on the carcinogenecity of prolonged exposure to low levels among the workers of a plant. Tijdschrift voor Economische en Sociale Geografie 51, 754-760.

Van Vleet, T.R., Klein, P.J., Coulombe, R.A., 2001. Metabolism of aflatoxin $\mathrm{B}_{1}$ by normal human bronchial epithelial cells. Journal of Toxicology and Environmental Health Part A $63,525-540$.

Van Vleet, T.R., Klein, P.J., Coulombe, R.A., 2002. Metabolism and cytotoxicity of aflatoxin $\mathrm{B}_{1}$ in cytochrome $\mathrm{p}-450$ expressing lung cells. Journal of Toxicology and Environmental Health Part A 65, 853-867.

$\mathrm{Wu}, \mathrm{F}$., 2004. Mycotoxin risk assessment for the purpose of setting international regulatory standards. Environmental Science and Technology 38, 4049-4055. 